\title{
Social Media \& Mental Health: A Narrative Study on Bangladesh during the Lockdown time of
} COVID-19 Pandemic

\author{
Amrita Nandy ${ }^{1}$, Mohona Biswas ${ }^{2}$, Joysree Das ${ }^{3}$ \\ ${ }^{1}$ Faculty of Business Administration, BGC Trust University Bangladesh, Chandanaish-4381, Chattagram, Bangladesh \\ ${ }^{2}$ Faculty of Business administration, Rangamati Science \& Technology University, Rangamati-4500, Bangladesh \\ ${ }^{3}$ Department of Pharmacy, BGC Trust University Bangladesh, Chandanaish-4381, Chattagram, Bangladesh \\ * Corresponding author
}

\begin{abstract}
Purpose: This study sheds light on the use of social media and its effects on mental health during the lockdown period of the COVID-19 pandemic in Bangladesh.

Methodology: A quantitative method has been followed to conduct the research. The purposive sampling method is adopted to gather responses from respondents through survey questionnaires during the lockdown period (May-July, 2021). The target populace is the respondents from the age of 18-60 who are highly active on social media in Bangladesh. In the end, 601 responses are obtained and a narrative approach has been used to assess the effects from various aspects like gender, occupation, and usage.
\end{abstract}

Findings: The study shows social media has a vast effect on people's mental health during the lockdown time in Bangladesh. $\mathbf{8 0 . 7 \%}$ of the sample use this media as a platform for social communication and $37 \%$ of respondents believe that the overall effects of social media are positive during this session. Additionally, research highlights a great engagement of young people in social media in Bangladesh which needs to restrain positively as this might hamper their mental health. Furthermore, results indicate that social media needs to respond more realistically and responsibly in time.

Implications: Being a strong and popular mode of communication as well as information, the governmental body can come across to formulate accurate policies in order to eradicate the negative consequences of social media during this pandemic. Recommendations suggested in this paper might be fruitful to develop a healthy communication platform even after the epidemic session in Bangladesh.

Keywords: Social Media; Bangladesh; Mental Health; Youth; COVID-19.

\section{INTRODUCTION}

$\mathrm{V}$ accination of COVID-19 or coronavirus has started in many countries as well as in Bangladesh. The disease, coronavirus (COVID-19) first identified at the end of December 19, 2019 in Wuhan city, China, and within a very short time it spreads worldwide. There are more than $4,163,955$ mortalities and about $194,252,788$ people globally affected by Coronavirus until July 24, 2021, In Bangladesh, the first case of the COVID-19 attack was identified in March of 2020 (Anam, 2020). There have been 1,146,564 confirmed COVID-19 cases with 18,851 deaths till 23 July 2021 (WHO Coronavirus COVID-19) Dashboard with Vaccination Data, 2021) and the number is mounting from time to time. Therefore, the Government of Bangladesh has undertaken various steps to neutralize the situation such as nationwide lockdown, closing all the government and private offices as well as the educational sector. The experience of social distancing and restrictions during lockdown exacerbated pessimistic feelings (Banerjee \& Rai, 2020; Porcelli, 2020) and thus the mental health is being affected. During this pandemic public have to know proper information about COVID-19 situation, symptoms of disease and up to date prevention techniques and for all of these, social media is the fast and effective platform for inquiring, and sharing healthrelated announcement towards the public (Bastani \& Bahrami, 2020; Zhao \& Zhang, 2017).

Social media is a platform to produce, receive, and share online content like online blogs, virtual games, and social networking sites (Boursier et al.,2020). Now-a-days people frequently express their emotions, conception, and intention using social media platforms. In Bangladesh, several types of internet-based social media are used but not all of them are popular. A study reveals that among the total users in Bangladesh; 89.12\% uses Facebook, 6.25\% uses YouTube, $1.42 \%$ Pinterest, $1.26 \%$ Twitter, $1.22 \%$ Linked In , and only $0.44 \%$ prefer to use Instagram from June 2020 to June 2021 (Bangladesh Charts 9m, 2021). Several studies have reported that the use of social media can help people to increase their recognized social support, self-esteem, happiness, and satisfaction (Pittman \& Reich, 2016) and thus improving their mental health. However, according to Boursier et al. (2020) engagement in social media during the pandemic may alleviate negative feelings because of distressing life circumstances.

Like many countries, educational institutes were closed for more than one and a half (1.5) years in Bangladesh in order to contain the virus. As a result, nearly 40 million students are now out of physical classes and campuses. This is why the 
concern of mental health during lockdown is rising worldwide day by day as students feel irritated or bored because the classes are not continuing as usual pattern and they can avail more time on social media compared to earlier stage (Swarnam, 2021). Many studies have been guided that using social media for a long time may be engaged to the sign and symptoms of mental stress, depression and anxiety (Berryman et al., 2018; Coyne et al., 2020; Escobar-Viera et al., 2018; O'reilly et al., 2019; O'Reilly et al., 2018; N. I. A. Rahman et al., 2013). Currently, mental illness is an emerging public health issue which is spreading worldwide and it has corresponding relationship with social media. According to an extended literature review, the perception and usage of social media varies on gender basis (Lin \& Lu, 2011; Lin \& Wang, 2020). Research by Scott et al. (2020) identified that women with excessive social media usage were more likely to suffer from mental depression than men as high social media usage can lead to low quality sleep, increase a person's loneliness, create unhealthy self-centeredness, and distance from friends and family (Sherrell, 2021).

Altogether, several pieces of investigation have been carried out focusing the effect of social media use on mental health during the imposed lockdown; surprisingly no current study has been carried forward to assess the potential effects of social media use on mental health during forced lockdown for COVID-19 crisis in Bangladesh. In light of the research evidence, it can be said that the news of mental illness is not at a satisfactory level during this lockdown period in Bangladesh. Again, people mostly young generation in Bangladesh are unaware of the rational use of social media and spending huge amount of time as leisure or other purposes. Hence, their mental health might be in question though physical safety is assured.

In this context, the present research seeks to bridge the gap by undertaking a primary study to understand the effect of social media during the lockdown in Bangladesh. In addition, the present study came up with multiple recommendations and successful implications of those might be fruitful to develop a healthy communication platform even after the epidemic session in Bangladesh.

\section{LITERATURE REVIEW}

Social networking is the right place to communicate content across the world rapidly, with posts like "breaking news" earning thousands of retweets in minutes (Swarnam, 2021). People use various kinds of social media to share information and thus easily they get connected with millions of users through social media. In this pandemic situation, the people of Bangladesh are highly attached to internet-based social media for knowing the up-to-date status of infection, an announcement of government, healthcare information, emergency support etc. A study shows that there were 47.61 million internet users in Bangladesh in January 2021 and it increased by 7.7 million (+19\%) between 2020 and 2021 (Bangladesh Charts 9m, 2021).. In the pandemic situation of
COVID-19, $71 \%$ loneliness (32\% mild, $29 \%$ moderate, $10 \%$ severe), $38 \%$ depression ( $24 \%$ mild, $11 \%$ moderate, $3 \%$ severe), $64 \%$ anxiety (30\% mild, $17 \%$ moderate, $17 \%$ severe) and $73 \%$ sleep disturbance $(50 \%$ mild, $18 \%$ moderate, $5 \%$ moderate) was estimated in Bangladesh (Das et al., 2021). 96,215 public posts were generated on Facebook with 584.51 million interactions in Bangladesh during the period March to December 2020 and all posts related to COVID-19. Martinsen (2008) states that not only the quality but also the quantity of social media topics shows an role on our physical health, mental health, health behavior, and mortality risk.

\subsection{The effect of social media on mental health}

Social restrictions during the COVID-19 pandemic have forced individuals to face a potentially terrifying reality of isolation (Banerjee \& Rai, 2020) thus, people worldwide have been invited to be socially (but not physically) connected (Courtet et al., 2020). Many recent studies on the role of the COVID-19 pandemic have revealed that the COVID-19 pandemic arises many troubles to the mental health of people worldwide (Brooks et al., 2020; Fiorillo \& Gorwood, 2020; Goyal et al., 2020; Sani et al., 2020) because it has disturbed people's routine life and lessened social contacts moreover it has increased anxiety, boredom, a sense of isolation, and frustration and thus risk of mental disorders has arisen (Boursier et al., 2020). In his paper, Ebesutani et al. (2015) indicated that restrictions during lockdown are positively related to mental illness and negatively related to the wellbeing, happiness, and life satisfaction of people (Salimi, 2011).

During Covid time, social media acts as a useful solution to reduce mental trauma by allowing people to stay connected and availing social support ( Wiederhold, 2020; Boursier et al., 2020). Use of social media has been highly recommended to obtain health and safety information and maintain social contacts in order to face the pandemic's isolation (American Psychological Association, 2020). The use of social media has been suggested as a provisional recovery from distress which needs to be carefully handled for facing loneliness and negative emotions (Wiederhold, 2020). Many scholars reported that social media tend to boost well-being, relationship quality, and social belonging (Sacco \& Ismail, 2014; Nowland et.al., 2018). Swarnam (2021) reported that most people use social media to communicate with their family, friends, and relatives and also for entertainment at lockdown and thus helping people to overcome any types of negativities related to mental health. Indeed, social media has been proposed as a tool for alleviating anxiety among individuals, even though the specific effects of social media consumption need to be carefully addressed (Wiederhold, 2020).

However, social media is often blamed for increasing mental health-related problems of people, particularly the young generation (Charles, 2019; The American Association of Suicidology, 2017). Similarly, the Royal Society for Public 
Health (2017) conducted a study and found that relationships exist between social media use and mental health issues. Not only the quality but also the quantity of social media topics shows the influence on people's physical health and mental health, behavior and mortality risk (Martinsen, 2008). Under the National Mental Health Survey, Bangladesh (2018-19), $6.7 \%$ of people have a depressive disorder, where $4.5 \%$ have anxiety, $2.1 \%$ have somatic symptoms and related disorders, $0.9 \%$ has sleep-wake disorder, $0.7 \%$ have obsessivecompulsive and related disorders, $0.3 \%$ have neurodevelopment disorder, $0.3 \%$ have neurocognitive disorders, $0.2 \%$ have substance-related and addictive disorders, $0.1 \%$ have a personality disorder, $0.1 \%$ have sexual dysfunction and $0.01 \%$ have disruptive, impulse control and conduct disorders (Rahman, 2019). Hence, social media addiction should be carefully examined (Kardefelt-Winther et al., 2017) especially during pandemic isolation (Király et al., 2020).

\subsubsection{The effect of social media on youth}

In modern era, the number of young people suffering from mental depression is alarming (Martinsen, 2008). Major depression suffered by adult (18-25 years) people has grown by 63\% from the year 2009 to 2017 (Clark, 2020). The impression of social media is most effective to the youth; for older the mental issue is not too much. Swarnam (2021) found that the social media increase the risk factor of mental health during COVID- 19 lockdown as students spend time 3 to 4 hours regularly on social media.

\subsubsection{The effect of social media on Gender}

Twenge and Martin (2020) explored gender differences in the usage of social media and females spent more time on social media sending more messages than males in U.S.A and UK. According to a literature survey by Kendler \& Myers (2014), the increase in poor mental health was stronger among women and youth compared to men. Women are significantly prone to mental depression than men in the absence of emotional support (Kendler et al., 2005). Boursier et al. (2020) reported that women tend to use social media in a dysfunctional way for balancing their negative moods which might have reinforced their mental health-related problems. Women tend to use social media for managing friendships, communicating with others whereas men use the said platform for getting information and playing online games (Krasnova et al., 2017). It is observed that women are not only more interested to use social media than men for social association (Frison \& Eggermont, 2015; Nowland et al., 2018) but also, they are more open to negative feelings (Boursier et al., 2020). National Institute of Mental Health, with the technical guide of the World Health Organization (WHO), operated National Mental Health Survey in Bangladesh from year 2018 to year 2019 and according to it, almost $16.8 \%$ man and $17 \%$ of women in Bangladesh were suffering from mental healthrelated problems. Scott et al. (2020) examined the effect of social networking site use on mental health on 1341 participants and reported that the risk for poor mental health was found stronger in women only. Kendler et al. (2005) conducted a study on sex differences in the relationship between social support and risk for major depression and found a relationship between excessive social media use and poor mental health of female participants.

\subsubsection{The effect of social media on sleep}

Social media has a host of unwanted consequences like reduced sleep quality and duration with resultant effects on overall health and daily performance (Harvey, 2020). Social media use is associated with poorer sleep, depression, and anxiety in young (Levenson, Shensa, Sidani, \& Colditz, 2016), who used high frequency of social media and are emotionally attached to that platform. Night-time social media use is linked to later bedtimes and delaying the sleep time, lessen sleep length, and quality induced by the worry of missing out (Scott \& Woods, 2018). Likewise, Das et al. (2021) observed that $73 \%$ of the general citizens in Bangladesh were suffering from sleep disturbance where $50 \%, 18 \%$, and $5 \%$ reported mild, moderate, and severe sleep disturbance during the COVID-19 pandemic.

\subsubsection{The effect of excessive time spent on social media}

Some studies have found an association between excessive time spent on social media and mental health problems, such as depression and anxiety (Barry, Sidoti, Briggs, Reiter, \& Lindsey, 2017; Coyne, et al., 2020). Study by Boursier et al. (2020) illustrates that respondents spent more hours on social media during the pandemic than earlier time. Their findings revealed that frequent social media use is related to increased mental health issues during the lockdown in Italy. Another research of Deepa and Priya (2020) established that too much time spent on social networking sites hampers student's mental health by accelerating depression and anxiety.

\subsubsection{The effect of social media on exercise}

Investigation of Swarnam (2021), highlighted that people did yoga or mediation to keep their physical and mental health stable during the lockdown period in India. Verious scholars (Revathy et al., 2018; Harvey, 2020) indicated that social media can be a useful platform to look for demonstrations of exercises and physical activities (like yoga) which can contribute to resist stress and depression especially to elderly people and to youth in the family

\section{RESEARCH METHODOLOGY}

\subsection{Population and Sampling Size}

The study focuses on the effects of social media on mental health of people during the lockdown period of the COVID-19 pandemic in Bangladesh. The target respondents for this research are the population of Bangladesh in the age range of 18-60 years who are highly active on social media platforms. The purposive sampling method was used to collect inputs from respondents through google forms which was sent 
through emails and various social media during the lockdown period in Bangladesh (May-July 2021). The research sample covers citizens who are staying in different parts of Bangladesh. Zikmund (2009) reported that if the population size is 100,000 or more, with a $95 \%$ confidence level, and a $5 \%$ error margin, the minimum sample size should be 322 . Initially 800 people were invited to participate in the survey. 743 responses were received. After screening, 142 responses had to reject due to incomplete responses. Finally, 601 responses were retained for final analysis where $72 \%$ were male and $28 \%$ were female.

\subsection{Data Collection}

A survey questionnaire was prepared with 15 items which was adopted from the study of Swarnam (2021) and distributed through an online survey to assess the perceptions of participants who use social media during the lockdown. The primary data includes the usage of all social media platforms like Facebook, WhatsApp, Instagram, etc. A total of 601 responses were collected and later the effects have been assessed from various aspects like gender, occupation, and usage of social media. Statistical tools like Microsoft Excel and Tables were used for narrative revision.

\subsection{Research Purposes}

The prime purpose of initiating this study is to understand the effect of social media on the mental health of people during the lockdown period of the COVID-19 epidemic. To attain this goal, the present research proposes the following specific research objectives:

1. To study people's usage pattern and purpose of using social media during lockdown period of Covid pandemic in Bangladesh.

2. To determine the effect of social media on mental health during the lockdown period of the pandemic in Bangladesh.

3. To find out some recommendations for further utilization of social media in Bangladesh during this epidemic time.

\section{FINDINGS AND DISCUSSIONS}

Figure 1: Respondents' summary

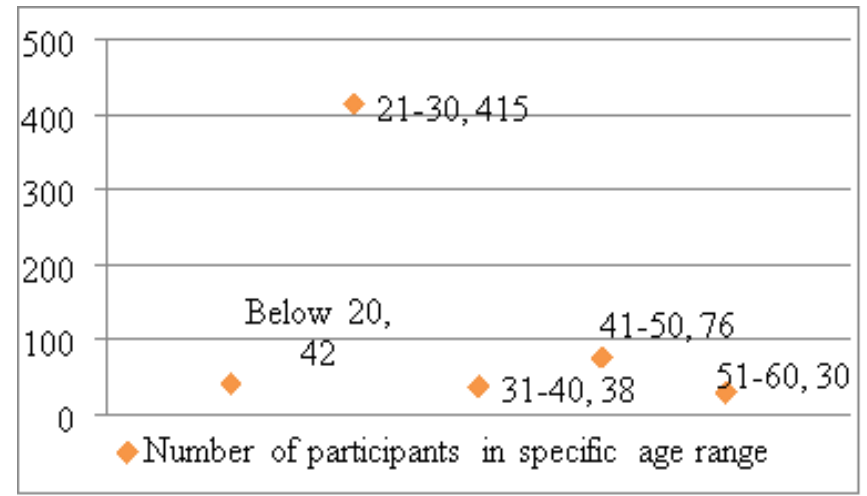

Figure 1, shows the classification of the respondents on age basis. The total sample is $601(n=601)$. In Bangladesh mostly young people use social media. Hence, a large group of the sample (415) falls in the age range between 21-30 years. Next, 76 people are from the age group of 41-50 years. Only 42 respondents are from below the age of 20.38 number of people represent the age range of 31-40 years. From the age group of 51-60 years, the sample size is only 30 . In Bangladesh, people from this group are not accustomed to technology much, as they rely less on social media. The response rate of females in the survey was also minimal compared to the male participation. In the sample $(n=601)$, there are $431(72 \%)$ male participants and the rest $170(28 \%)$ are females

Figure 2: Respondents' classification based on occupation

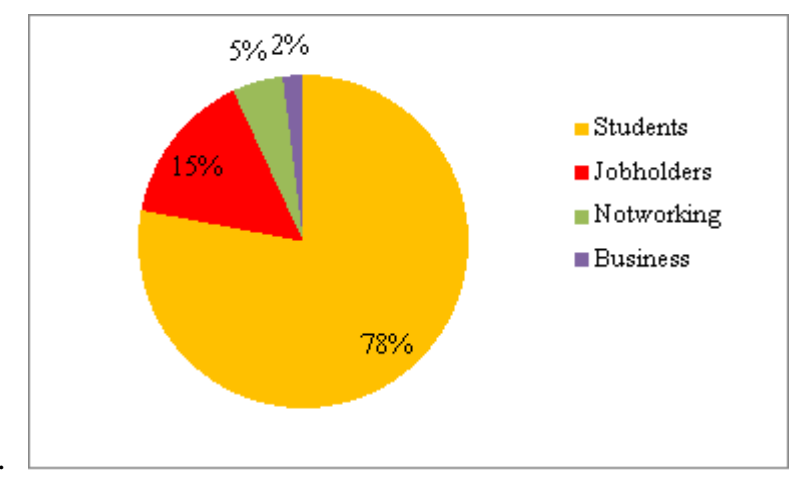

In the above pie chart, the total respondents have been categorized based on their occupation to use social media. Again students $(78 \%)$ are dominating usage of social media. Job holders or working people hold $15 \%$, while only $2 \%$ of the respondents belong to business people, as they mostly use their own networks (websites, emails, or phone calls) to communicate and to conduct online business.

Figure 3: Common platforms of social media

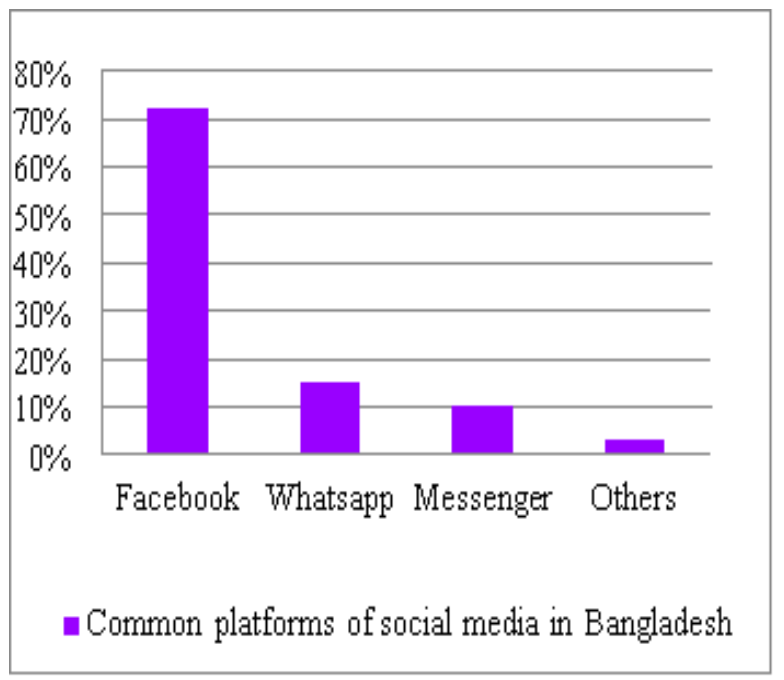

Names of the commonly used social media platforms are enlisted with the usage percentage in figure 3. In Bangladesh, 
young people mostly use Facebook (72\% users) which is very popular even in rural areas. After that, jobholders along with professionals prefer WhatsApp (15\%) for social communications. $10 \%$ of the responses are connected through messenger. However, few responses are friendly to use other platforms (LinkedIn, Instagram etc.) in Bangladesh.

Figure 4: Gender wise purpose behind using social media

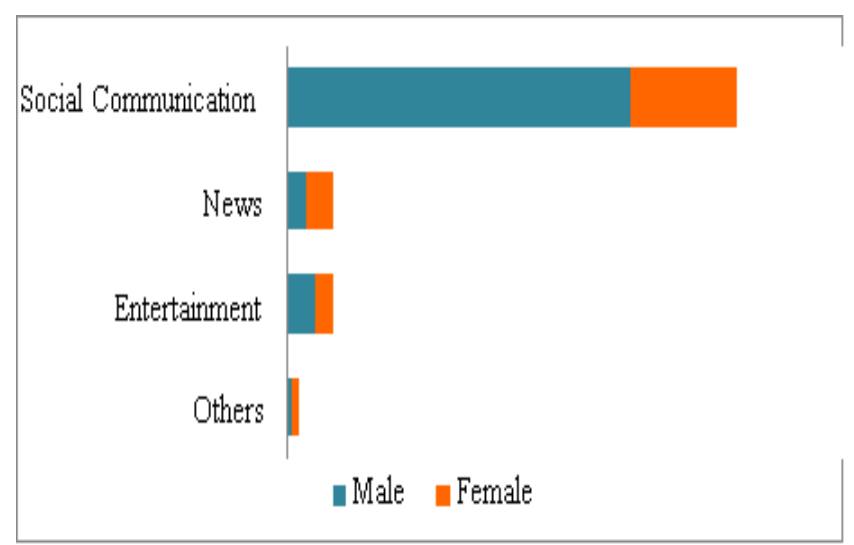

Through figure 4, gender-wise participation is drawn with the purpose behind using social media. Here, it is noticeable that males use social media at large compared to females. A large portion of male participants $(87 \%)$ use social media to communicate. Interestingly, for news, women (57\%) rely more on social media compared to men (43\%). On contrary, for entertainment, males $(59 \%)$ use social media mostly than females $(41 \%)$.

Figure 5: Overall perception of the people towards social media

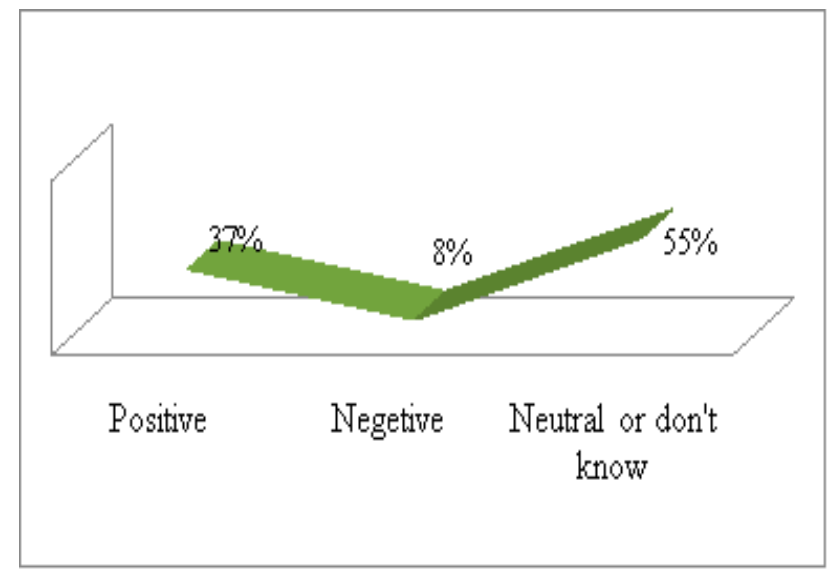

Figure 5 highlights the overall perception of the people towards social media in Bangladesh. $37 \%$ of the respondents have considered that social media acts positively during the lockdown period; whereas, $8 \%$ of them have spoken about the negative effects of social media. Surprisingly, over half of the respondents $(55 \%)$ do not evaluate the performance of social media, which is a general lifestyle of people in Bangladesh.
Figure 6: Gender-wise effects of social media on mental health

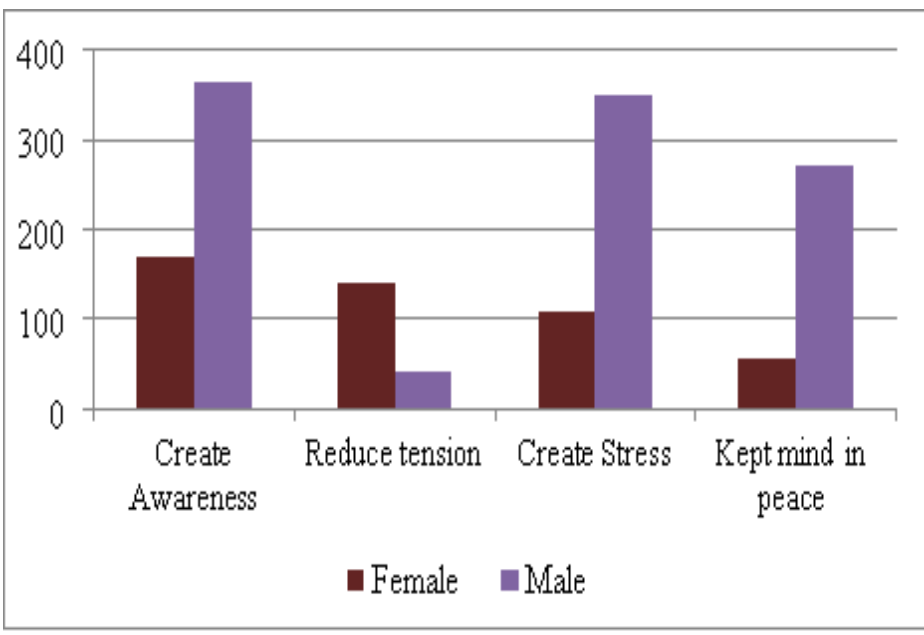

Figure 6 portraits the gender wise effects of social media on mental health during the lockdown phase of the COVID-19 pandemic in Bangladesh. 363 male respondents $(60 \%$ of $n=$ 601) have shared that social media created awareness while 348 male participants $(58 \%$ of $n=601)$ have accused social media of causing stress during the lockdown period. Only $7 \%$ of male respondents (43 in number) think that social media helped to reduce tension. From women's viewpoint, $28 \%$ of them have agreed in awareness creation while the other $23 \%$ agreed social media works in tension reduction. On contrary, 110 respondents ( $9 \%$ of $n=601$ ) consider the use of social media has risen their stress level in lockdown duration. In short, compared to men, women's perceptions of social media's effectss are more positive in moral development during the lockdown period.

Figure 7: Occupation wise effects of social media on mental health

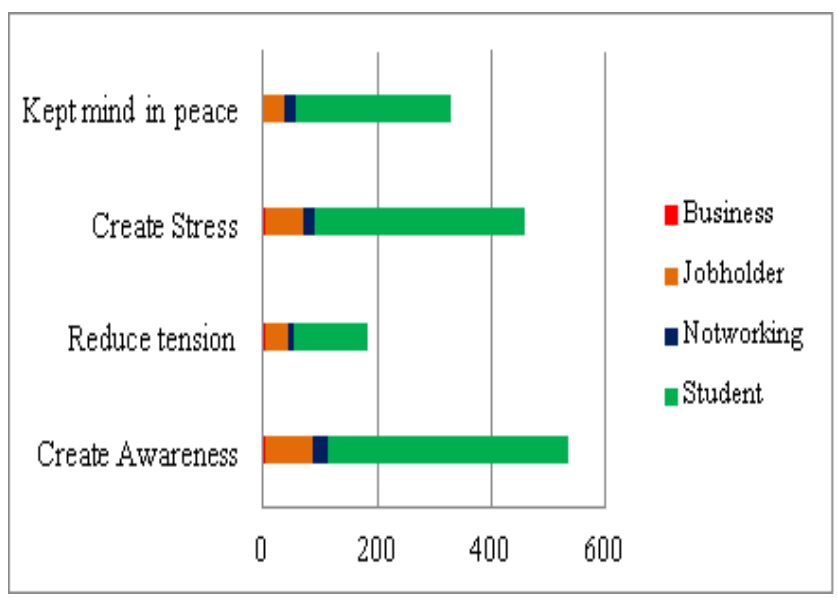

From figure 7, the occupation-wise effects can be assessed. As mentioned earlier, more than half of the participants remained neutral towards social media's effects. Among the rest, $89 \%$ of the respondents agreed that social media worked to create awareness. On the contrary, $77 \%$ think social media caused stress. Again, more than half $(55 \%)$ of them believe social 
media worked to keep their mind in peace during this hard time of the covid pandemic. In addition, $31 \%$ of the samples think the use of social media reduced their tension level. As students cover the sample mostly, in their opinion the effects are more positive, while jobholders remain indifferent as an equal number of them agreed on awareness creation and stress stimulation. Moreover, participants from the "business" and "not working" categories also pointed that social media helped to enhance the morale (through awareness creation, tension reduction, and safeguarding the mind in peace) during the lockdown timeframe of this epidemic.

Figure 8: Daily usage of social media

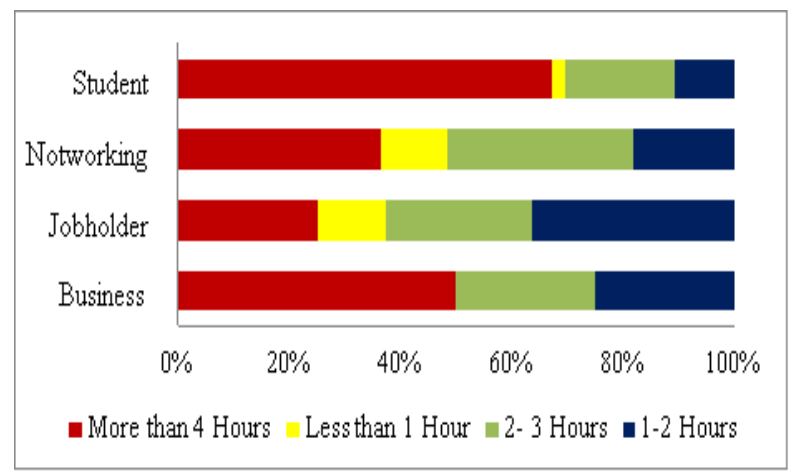

In order to contain the disease, the educational institutions in Bangladesh remained closed for more than a year. As a result, students can spend more time on social media, which is reflected in figure 8 . More than $65 \%$ of university students use social media for more than 4 hours, while $20 \%$ of them use it for 2-3 hours daily. Business people are the next large consumer $(50 \%)$, who were spending time more than 4 hours in a day on social media. The usage varies from 2-3 hours for $25 \%$ of business holders as well. Interestingly, $35 \%$ of people (not working) employ more than 4 hours while around $23 \%$ of them use it for 2-3 hours on regular basis. This group mainly looks for social communication. Conventionally, nearly $40 \%$ of jobholders use social media for 1-2 hours as work from home continued even in lockdown sessions of the COVID-19 epidemic. $25 \%$ of them use it for $2-3$ hours or even for more than 4 hours.

Figure 9: Usage pattern of social media

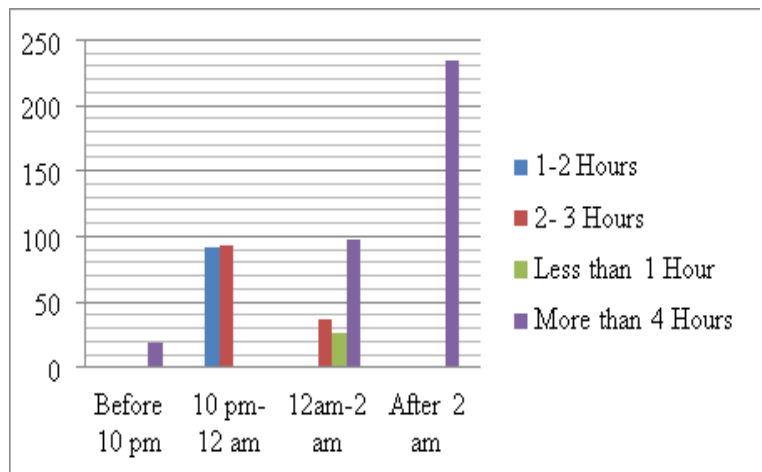

Figure 9 presents the usage pattern of social media. Only 3\% of respondents prefer to use social media before $10 \mathrm{pm}$ that continues for more than 4 hours. Substantial used of this platform starts from 12 am to 2 am. $40 \%$ of people from the sample $(n=601)$, who use social media for more than 4 hours habitually choose to be active after $2 \mathrm{am}$. As the majority of the respondents are university students this can be an alarming sign as such practice may hamper their study and mental health immensely.

Figure 10: Habitual use of social media during lockdown period

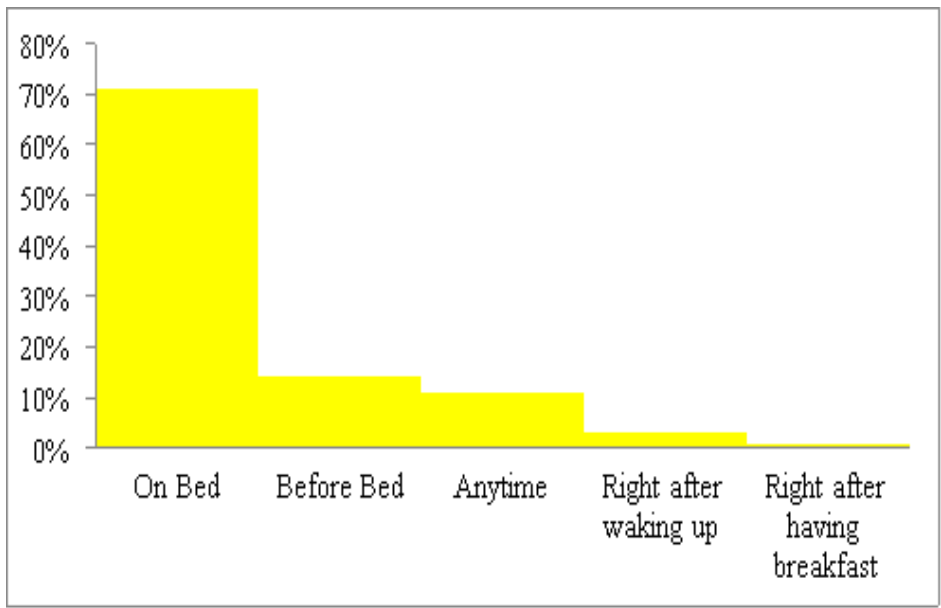

From figure 10, again the adverse effects of social media usage can be drawn. More than $70 \%$ of people commonly used social media on the bed that eventually hamper their sleep, relaxation as well as mental health. Another $3 \%$ of respondents have shared their craving to check the social media right after waking up which also has negative consequences on mental health. Only $1 \%$ of the total sample $(n=601)$ are habituated to use social media after completing breakfast. In addition, $14 \%$ of the participants have good practice to rest the social media usage before bed.

Figure 11: People's indoor activities to lower the stress level in lockdown time

\begin{tabular}{|l|c|c|c|c|}
\hline & \\
\hline Students & 271 & 29 & 5 & 164 \\
\hline Not working & 11 & 1 & 1 & 20 \\
\hline Jobholders & 28 & 5 & 3 & 55 \\
\hline Dusiness & 3 & & & 5 \\
\hline
\end{tabular}


Figure 11 represents people's involvement in various indoor activities in order to minimize the stress or negative consequences of the lockdown time in Bangladesh. Noticeably, $52 \%$ of people have started conducting physical exercises while another $6 \%$ of respondents have followed meditation sessions during this period. Only $2 \%$ of people need to take medicine. Interestingly, business people are not following either meditation or medication. While surprisingly, a very small portion of students $(1 \%)$ need to take medication to get rid of their anxiety and depression. However, $41 \%$ of the participants engaged themselves in other activities to keep themselves healthy and stress-free.

Figure 12: Respondents expectation towards social media during pandemic hurdles

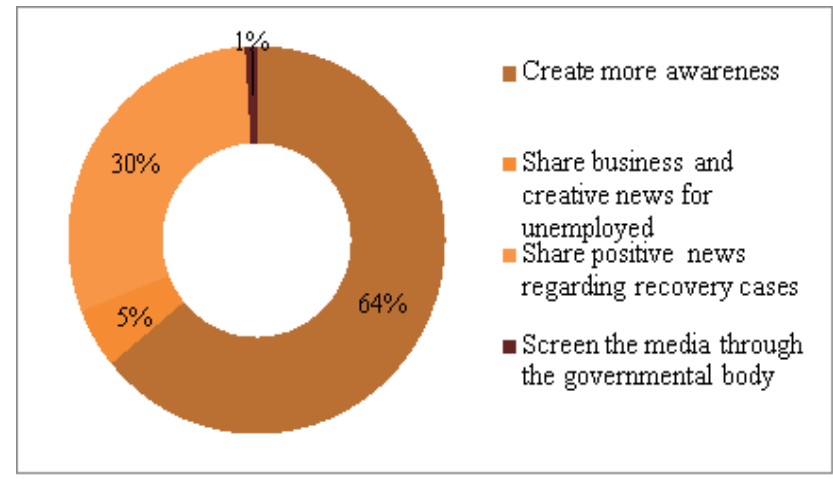

Figure 12, displays people's expectations towards social media to get rid of this crisis, to enhance the moral vibes, and to fight back against the virus. A large number of respondents have emphasized more awareness creation $(64 \%)$ and sharing positive information $(30 \%)$. Surprisingly, $1 \%$ of people have wished that the government should monitor these media in order to cut off the negative consequences.

\section{RECOMMENDATIONS}

Social media has extensive power to influence and to link the peoples through information (news as well as communication). Various platforms of social media are driving people not only to learn but also to take action accordingly. During this time of social distancing, it is the only mechanism to associate the person in a group. Therefore, the importance of this mode of communication has risen compared to the earlier time of the pandemic. Meanwhile, individuals at present need to take proper care of mental health along with physical wellbeing. As a result, the effects of social media need to evaluate mostly than before and corrective actions need to be taken in proactive manner. The below recommendations will contribute to enrich people's moral and mental stability while using social media during and after the epidemic period.

\subsection{Community Awareness}

Community-based groups can be created to share COVID-19 related facts like infected cases and infection rates, treatment and diagnosis, successful recovery calculation, and actual vaccination records. In such way, the negative effects, as well as news falsification, can be reduced. Again, such initiative will work to enhance morality and bonding among community members in an emergency. Moreover, to safeguard people against misinformation, public health organizations and governments should create and share accurate news on social media as these platforms can significant impact on policy making and health education.

\subsection{Duties of Educational institutions}

It is alarming that a vast number of university students are spending more than 4 hours daily especially at night for searching entertainment on social media. In Bangladesh, all educational institutions are shut down for nearly 2 years while online learning is continuing in this period. As a result, educational institutions need to play a proactive role to engage students to upgrade their creative, analytical, and logical capabilities by utilizing information technology rather than concentrating on the traditional educational systems (providing lessons only). Besides the conventional curriculum, the study instruments need to develop in a more resourceful mode to influence students to invest their time in search of knowledge in social media rather than entertainment.

\subsection{Family Enforcement (bonding and education)}

As the young generation (age 18-30) are staying home for a longer period, generally it is retarding their mental development. Family needs to inspire them for better lifestyle and healthcare as well as to develop their righteous characteristics rather than imposing more stress and causing depression regarding the future. This juvenile can grip themselves in household activities and involving creative activities through social media can increase cognitive skills also. In all these, the family needs to play an important part to encourage students to maintain bonding among the family members.

\section{$5.4 \quad$ Local governance}

Within the crisis of COVID-19, local governments need to act and take more responsibilities besides their regular duties. Organizations of a local government body can initiate community or locality-wise assistance for old and people in need via social media. Using social media, series of "free online social workshops" for soft skill training, healthcare, financial services, craft ship can be launched where students can lead the society. Under the local government's supervision, young people can come forward to help and to support the aged person and those infected people (as well as their families) who demand moral support.

\subsection{Ensuring self-governance of social media}

Being a democratic country, social media cannot be controlled centrally; however, the government can negotiate with the respected owners for self-governance in order to establish 
real-time monitoring surveillance and to minimize the negative effect of those social media.

\subsection{Connect people in need}

In an emergency, information is helpful only if it is accurate and on time. "Emergency needs" like COVID-19 vaccinations or treatments can be arranged on spot in a community or on a priority basis where the use of social media can be helpful to spread the facts quickly. In addition, the affected person and the family require more help, support, and care which can be smoothly coordinated through social media, only if such platform is utilized in a proper manner.

\subsection{Utilize the database for policymaking}

Though it requires time to uproot an epidemic travail completely, various strains of the COVID-19 virus have been thrashing mankind periodically in the last 2 years. In future, that virus may come as seasonal. As a result, it might be useful to establish a real-time model to monitor the trend and side effects of COVID-19 diseases. Besides governmental records, current and accurate databases in social media can also be beneficial to study the mutation nature of this virus as well as disease patterns nationwide. Thus, it will help the policymakers to draw suitable policies that will make life more comfortable and safer to conduct daily activities. Additionally, preventative actions need to be taken to boost literacy about the rational use of social media and to avoid the risks associated with excessive social media use during pandemics.

\subsection{Focus more on mental health}

Being confined at home for a long time has adverse effects on mental health. At present, mental health deserves indistinguishable attention along with physical well-being. Especially for elderly people, for youth and for children, society as well as policymakers need to look beyond the horizon. In every social media, an "open zone" can be established voluntarily by social figures for counseling where public share their grievance and sufferings that have arisen at the epidemic spike.

\section{IMPLICATION}

From theoretical ground, the study has vast implications. While people mostly aware about the positive aspects and consequences of the social media, this paper signify some of its negative effects. Though it does not establish the total negative or positive effects of this media- yet, this is high time for the government as well as for respective society (including parents) to keep an eye on the overall performance of the social media. From practical perspective, during this epidemic, social media is playing an indisputable role to connect and to help people to a large extent. However, the performance need to redirect as a more reliable and optimistic way. Additionally, students' involvement in this media also needs to monitor and they need to engage themselves in a more proactive and fruitful manner to render social support and to encourage people who are in real help. Finally, policymakers can develop a detail plan to guide the local government along the society by following the recommendations which are discussed in this paper.

\section{LIMITATIONS}

In particular, information about the participants' overall health status has not been collected in this study before and during the pandemic. Though it has covered 601 responses, yet the sample size is small compared to the total user of social media in Bangladesh. All most responses got from the male gender that cannot represent all genders and whatever conclusions are made. Again, the research was conducted over a short period. Lastly, not all the people might be sincere while answering the questionnaire. So, the validation of the responses is in question.

\section{FUTURE RESEARCH DIRECTIONS}

Further researchers could explore whether the use of specific social media is related to excessive involvement to hamper mental and physical health simultaneously and could specify an age group who are addicted users (students or aged people). Assessing the true success of social media during this pandemic might be an additional study topic. Finally, based on this variable, another study can also be conducted aiming to identify the road map to uplift the rational use of social media and possible solutions to avoid the threat associated with its extreme use.

\section{CONCLUSION}

Social media has far-reaching significance beyond realization, it has seen that globally most of the government $(87 \%)$ connected through social media with their public (Chakrabarti, 2018). Policymakers need to utilize this opportunity of information technology to ensure safety (awareness to stay home), to establish well communication (vaccination, treatment, counseling, education, and lifestyle) and to render better support (help people in crisis). In this epidemic, where social distancing is the one step ahead measure to mitigate the virus, it is the social media (because of their user base as well) that is providing a glimmer of hope; a feeling of belongingness and care (moral, financial, and commodity). Indeed, it should turn into the faithful media through which the kindness of known and unknown persons will be gratified and humanity will be restored.

\section{REFERENCES}

[1] American Association of Suicidology. (2017). Social Media's Role on Young People's Mental Health is Real. Available online at: $\quad$ https://www.mhafred.org/social-medias-role-on-youngpeoples-mental-health-is-real/

[2] Amichai-Hamburger, Y., \& Ben-Artzi, E. (2003). Loneliness and Internet use. Computers in Human Behavior, 19(1), 7180. https://doi.org/10.1016/S0747-5632(02)00014-6

[3] Anam, M. (2020, March 9). First coronavirus cases confirmed. The Daily Star. Retrieved from https://www.thedailystar.net/frontpage/news/first-coronaviruscases-confirmed-1878160 
[4] Banerjee, D., \& Rai, M. (2020). Social isolation in COVID-19: the role of loneliness. International Journal of Social Psychiatry, 66, 525-7. doi: 10.1177/0020764020922269

[5] Bangladesh charts 9m new social media users. (2021, April 26). Dhaka Tribune . Retrieved from https://www.dhakatribune.com/bangladesh/2021/04/26/bangladesh -charts-9m-new-social-media-users

[6] Bastani, P., \& Bahrami, M. A. (2020). COVID-19 Related Misinformation on Social Media: A Qualitative Study from Iran (Preprint). Journal of Medical Internet Research. https://doi.org/10.2196/18932

[7] Berryman, C., Ferguson, C. J., \& Negy, C. (2018). Social Media Use and Mental Health among Young Adults. Psychiatric Quarterly, 89(2), 307-314. https://doi.org/10.1007/s11126-0179535-6

[8] Bilgin, O., \& Tas, I. (2018). Effects of perceived social support and psychological resilience on social

media addiction among university students. Universal Journal of Educational Research, 6, 751-8. doi: 10.13189/ujer.2018.060418

[9] Boursier, V., Gioia, F., Musetti, A. \& Schimmenti, A. (2020). Facing Loneliness and Anxiety During the COVID-19 Isolation: The Role of Excessive Social Media Use in a Sample of Italian Adults. Front. Psychiatry 11:586222. doi: 10.3389/fpsyt.2020.586222.

[10] Barry, C. T., Sidoti, C. L., Briggs, S. M., Reiter, S. R., \& Lindsey, R. A. (2017). Adolescent social media use and mental health from adolescent and parent perspectives. Journal of Adolescence, 61, 1-11. https://doi.org/10.1016/j.adolescence.2017.08.005

[11] Brooks, S. K., Webster, R.K., Smith, L.E., Woodland, L., Weissley, S., \& Greenberg, N. (2020). The psychological role of quarantine and how to reduce it: rapid review of the evidence. Lancet, 395, 912-20. doi: 10.1016/S0140-6736(20)30460-8

[12] Chakrabarti, S. ( 2018). Hard Questions: What Effect Does Social Media Have on Democracy? Retrieved from (https://about.fb.com/news/2018/01/effect-social-mediademocracy/)

[13] Charles, S. (2019). Social media linked to rise in mental health disorders. Accessed online at: https://www.nbcnews.com/health/mental-health/social-medialinked-rise-mental-health-disorders-teens-survey-finds-n982526.

[14] Clark, M. (2020). 40+ Frightening Social Media and Mental Health Statistics Retrieved from https://etactics.com/blog/socialmedia-and-mental-health-statistics

[15] Courtet, P., Olié, E., Debien, C., \& Vaiva, G. (2020). Keep socially (but not physically) connected and carry on: preventing suicide in the age of COVID-19. J Clin Psychiatry, 81, e20com13370-e20com13370. doi: 10.4088/JCP.20com13370

[16] Coyne, S. M., Rogers, A. A., Zurcher, J. D., Stockdale, L., \& Booth, M. (2020). Does time spent using social media role mental health?: An eight year longitudinal study. Computers in Human Behavior, 104, 106160. https://doi.org/10.1016/j.chb.2019.106160

[17] Deepa M, D \& Priya, K. (2020). Role of social media on mental health of students. International Journal of Scientific \& Technology Research, 9 (3). 3796-3800. https://www.researchgate.net/publication/340779328

[18] Ebesutani, C., Fierstein, M., Viana, A.G., Trent, L., Young, J., Sprung, M. (2015). The role of loneliness in the relationship between anxiety and depression in clinical and school-based youth. Psychol Schools, 52, 223-34. doi: 10.1002/pits.21818

[19] Escobar-Viera, C. G., Whitfield, D. L., Wessel, C. B., Shensa, A., Sidani, J. E., Brown, A. L., Chandler, C. J., Hoffman, B. L., Marshal, M. P., \& Primack, B. A. (2018). For better or for worse? A systematic review of the evidence on social media use and depression among lesbian, gay, and bisexual minorities. JMIR Mental Health, 5(3), 1-14. https://doi.org/10.2196/10496

[20] Fiorillo, A., \& Gorwood P. (2020). The consequences of the COVID-19 pandemic on mental health and implications for clinical practice. Eur Psychiatry, 63, e32. doi: $10.1192 /$ j.eurpsy.2020.35
[21] Frison, E., Eggermont, S. (2015). Exploring the relationships between different types of facebook use, perceived online social support, and adolescents depressed mood. Social Science Computer Review, 34(2),153-71.

[22] Goyal, K., Chauhan, P., Chhikara, K., Gupta, P., Singh, M.P. (2020). Fear of COVID 2019: first suicidal case in India! Asian J Psychiatry, 49, 101989. doi: 10.1016/j.ajp.2020.101989

[23] Harvey, C. (2020). The Effects of Social Media on Stress. Retrieved from https://cliffharvey.com/the-effects-of-socialmedia-on-stress/

[24] Kardefelt-Winther, D., Heeren, A., Schimmenti, A., VanRooij, A., Maurage, P., Carras, M. (2017). How can we conceptualize behavioural addiction without pathologizing common behaviours? Addiction, 112, 1709-15. doi: 10.1111/add.13763

[25] Kendler, K.S., Myers, J., \& Prescott, C.A. (2005). Sex differences in the relationship between social support and risk for major depression: a longitudinal study of opposite-sex twin pairs. Am J Psychiatr, 162(2),250-6.

[26] Kendler, K.S., Myers, J. (2014). The boundaries of the internalizing and externalizing genetic spectra in men and women. Psychol Med, 44, 647-55. doi: 10.1017/S0033291713000585

[27] Király, O., Potenza, M.N., Stein, D.J., King, D.L., Hodgins, D.C., Saunders, J.B. (2020). Preventing problematic internet use during the COVID-19 pandemic: consensus guidance. Compr Psychiatry, 100,1-4. doi: 10.1016/j.comppsych.2020.152180

[28] Krasnova ,H., Veltri, N.F., Eling, N., \& Buxmann, P. (2017). Why men and women continue to use social networking sites: the role of gender differences. J Strateg Inf Syst, 26(4), 261 -84.

[29] Martinsen, E. W. (2008). Physical activity in the prevention and treatment of anxiety and depression. Nordic Journal of Psychiatry, 62 (47), 25-29. https://doi.org/10.1080/08039480802315640

[30] Mental health issues increased significantly in young adults over last decade: Shift may be due in part to rise of digital media, study suggests (2019, March 15). ScienceDaily.

[31] Levenson, J. C., Shensa, A., Sidani, J. E., Colditz, J. B., \& Primack, B. A. (2016). The association between social media use and sleep disturbance among young adults. Preventive medicine, $85,36-41$.

[32] Lin, K. Y., \& Lu, H.- P. (2011). Why people use social networking sites: An empirical study integrating network externalities and motivation theory. Computers in Human Behavior, 27(3), 11521161. 12

[33] Lin, X., \& Wang, X. (2020). Examining gender differences in people's information-sharing decisions on social networking sites. International Journal of Information Management, 50, 45-56.

[34] Nowland, R., Necka, E. A., \& Cacioppo, J.T. (2018). Loneliness and social internet use: pathways to reconnection in a digital world? Perspect Psychol Sci, 13, 70-87. doi: $10.1177 / 1745691617713052$

[35] O'reilly, M., Dogra, N., Hughes, J., Reilly, P., George, R., \& Whiteman, N. (2019). Potential of social media in promoting mental health in adolescents. Health Promotion International, 34(5), 981-991. https://doi.org/10.1093/heapro/day056

[36] O'Reilly, M., Dogra, N., Whiteman, N., Hughes, J., Eruyar, S., \& Reilly, P. (2018). Is social media bad for mental health and wellbeing? Exploring the perspectives of adolescents. Clinical Child Psychology and Psychiatry, 23(4), 601-613. https://doi.org/10.1177/1359104518775154

[37] Peper, E., \& Harvey, R. (2018). Digital addiction: increased loneliness, anxiety, and depression. Neutoregulation, 5,3-8. doi: 10.15540/nr.5.1.3

[38] Pittman, M., \& Reich, B. (2016). Social media and loneliness: why an Instagram picture may be worth more than a thousand Twitter words. Computers in Human Behavior, 62,155-67. doi: 10.1016/j.chb.2016.03.084

[39] Polizzi, C., Lynn, S.J., \& Perry, A. (2020). Stress and coping in the time of COVID-19: pathways to resilience and recovery. Clin Neuropsychiatry, 17, 59-62. doi: 10.36131/CN20200204

[40] Porcelli, P. (2020). Fear, anxiety and health-related consequences after the COVID-19 epidemic. Clin Neuropsychiatry, 17, 103-11. 
doi: $10.36131 / \mathrm{CN} 20200215$

[41] Rahman, M. (2019, November 7). 16.8\% Bangladeshi adults suffer from mental health issues. Dhaka Tribune. Retrieved from https://www.dhakatribune.com/bangladesh/dhaka/2019/11/07/surv ey-nearly-17-of-bangladeshi-adults-suffer-from-mental-healthissues

[42] Rahman, N. I. A., Ismail, S., Seman, T. N. A. B. T., Rosli, N. F. A. B., Jusoh, S. A. B. M., Dali, W. P. E. W., Islam, M. Z., \& Haque, M. (2013). Stress among preclinical medical students of university sultan zainal abidin. Journal of Applied Pharmaceutical Science, 3(11), 76-81. https://doi.org/10.7324/JAPS.2013.31113

[43] Revathy, V., Aram, I., \& Sharmila, V. (2018). Social media as a means to overcome stress and depression among women. Journal of Media and Communication Studies, 10(6), 46-64.

[44] Royal Society for Public Health. (2017). Social media and young people's mental health and wellbeing. Available online at: https://www.rsph.org.uk/our-work/campaigns/status-of-mind.html

[45] Sacco, D.F., \& Ismail, M.M. (2014). Social belongingness satisfaction as a function of interaction medium: face-to-face interactions facilitate greater social belonging and interaction enjoyment compared to instant messaging. Computers in Human Behavior, 36, 359-64. doi: 10.1016/j.chb.2014.04.004

[46] Salimi, A. (2011). Social-emotional loneliness and life satisfaction. Proc Soc Behav Sci, 29, 292-5. doi: 10.1016/j.sbspro.2011.11.241

[47] Sani, G., Janiri, D., Di Nicola, M., Janiri, L., Ferretti, S., \& Chieffo, D. (2020). Mental health during and after the COVID-19 emergency in Italy. Psychiatry Clin Neurosci, 74, 372. doi: 10.1111/pcn.13004

[48] Scott, E. S., Canivet, C., \& Ostergren, P. (2020). Investigating the effect of social networking site use on mental health in an 18-34 year-old general population; a cross-sectional study using the 2016 Scania Public Health Survey. BMC Public Health, 20, 1753. Doi: 10.1186/s12889-020-09732-z.
[49] Scott, H., \& Woods, H.C. (2018). Fear of missing out and sleep: Cognitive behavioural factors in adolescents' nighttime social media use. Journal of Adolescence, 68, 61-65. doi: 10.1016/j.adolescence.2018.07.009.

[50] Sherrell, Z. (2021, September 15). What to know about social media and mental health. Medical News Today. Retrieved from https://www.medicalnewstoday.com/articles/social-media-andmental-health\#negative-effects

[51] Swarnam, S. (2021). Effect of Social Media Use on Mental Health during Lockdown in India. ArXiv, abs/2102.09369. Retrieved from https://arxiv.org/abs/2102.09369

[52] Twenge, J. M., Cooper, B.A., Joiner, E. T., Duffy, E. M., \& Binau, G. S. (2019). Age, Period, and Cohort Trends in Mood Disorder Indicators and Suicide-Related Outcomes in a Nationally Representative Dataset, 2005-2017. Journal of Abnormal Psychology, 128 (3), 185-199. doi.org/10.1037/abn0000410

[53] Twenge, J. M., \& Martin, G. (2020). Gender differences in associations between digital media use and psychological wellbeing: Evidence from three large datasets. Journal of Adolescence, 79(2020), 91-102ISSN

0140-1971 https://doi.org/10.1016/j.adolescence.2019.12.018

[54] WHO Coronavirus COVID-19) Dashboard with Vaccination Data. (2021). Bangladesh: WHO Coronavirus Disease (COVID-19) Dashboard With Vaccination Data . Retrieved from https://covid19.who.int/region/searo/country/bd

[55] Wiederhold, B.K. (2020). Using social media to our advantage: alleviating anxiety during a pandemic. Cyberpsychol Behav Soc Netw, 23, 197-8. doi: 10.1089/cyber.2020.29180.bkw

[56] Zhao, Y., \& Zhang, J. (2017). Consumer health information seeking in social media: a literature review. Health Information and Libraries Journal, 34(4), 268-283. https://doi.org/10.1111/hir.12192

[57] Zikmund, W. G. (2009). Business Research Methods (8th ed.). The Dryden Press, Fort Worth. 